\title{
Presence of Tyloses in 6 Korean Oak Species for Production of Liquor Barrels and Correlation of Retention of Large Vessel Lumen
}

\author{
Min Ji Kim, Yoon Seong Chang, Jin teak Kang, Joo won Lee, and Chang Deuk Eom * \\ This study was conducted to devise ways of promoting the use of \\ deciduous trees that have increased in number with climate change. For \\ six oak species commonly utilized to produce liquor barrels, normal wood \\ and tension wood were classified by part. Then, both large vessel lumen \\ area and tyloses were quantitatively assessed. The findings showed that \\ in both normal and tension woods, large vessel lumen area was largest in \\ sapwood, followed by heartwood and juvenile wood. Tyloses were found \\ in both normal and tension woods of all the six species, but the number of \\ tyloses varied according to species. It was heart wood that contained the \\ highest amount in both normal and tension woods. It was also revealed \\ that the number of tyloses decreased with the growing area of large vessel \\ lumen. This study will provide fundamental data to decide oak tree species \\ for the production of liquor barrels.
}

DOI: 10.15376/biores.17.1.1364-1372

Keywords: Wood anatomy; Tyloses; Quercus spp.; Oak; Liquor barrels

Contact information: Department of Forest Products, National Institute of Forest Science, Seoul 02455, Republic of Korea; *Corresponding author: willyeom@korea.kr

\section{INTRODUCTION}

In the past, Korean alcohol was made from rice and liquor, but it began to open its eyes to Western traditional liquor as it opened the door to the world. For instance, the domestic wine market has increased by more than 10\% annually since 1987 (You 2013). Traditional Western spirits are mainly made from grains, potatoes, and fruits, and mostly produced by aging in oak barrels. When alcohol is matured in an oak barrel, the unique chemical ingredients of wood combine with the alcohol to form the characteristics of traditional liquor. Volatile ingredients and phenolic compounds change the flavor of wine, improving its overall quality (Cerdán et al. 2002). However, not all oak barrels have the uniform number of compounds. They all have different characteristics depending on the production area and environment (Frangipane and De Santis 2007), which play a major role in the characteristics of oak barrels. Not all timber can turn into these barrels. The name "Oak Tong," a Korean catch-all term for wooden barrels, is associated with the characteristics of oak trees. Wood is a porous material that has an intracellular pathway for transporting water and nutrients. Ordinary wood therefore tends to be leaky. Thus, only certain species have been used as liquor casks, where structures that block the fluid passage develop. The common reason why liquor containers are called "oak tong" is that they are made from oak trees. 
Oak trees have 1 to 3 rows of vessels that transfer water into these cells. The wood also consists of fluid cells and wood fibers. The aforementioned structure is key to the development of tyloses in a vessel. A condition known as tylosis is produced when parenchyma cells burst open as they are in the process of entering into lumen spaces. According to the literature, cell walls of tyloses of oak trees are divided into primary and secondary walls, whose thickness ranges from 0.3 to $0.5 \mu \mathrm{m}$ for the primary and 1.4 to 2.6 $\mu \mathrm{m}$ for the secondary (Park et al. 2006). Some species possess only primary walls (Lidija 1975). Subspecies of oak trees range from red oak to common white oak. Other species include ash (Fraxinus rhynchophylla) and chestnut (Castanea crenata), and the number of tyloses in them varies. Also, sparkling properties associated with tyloses can be observed in some species such as the black locust tree (Bruce 1990). Previous studies have identified that tyloses develop when the wood is transformed into heartwood, but for domestic mongolica oak and acacia trees, tyloses are also formed in infancy during the period when age formation is active. Sayaka et al. (2013) found that tyloses emerge in the sapwood of acacia trees but depends on the moisture content of the outermost part of the sapwood, which is active when the moisture content of the vessel is low. In other cases, tyloses may also occur in branches that have not developed into heartwood when sawtooth oak is used as materials for construction, ships and liquor barrels (Lee and Park 2009). Further research on how tyloses are generated is needed.

Tyloses in wood affect its usage. Tyloses in the vessels are produced to prevent substances from leaking. This wood could then be utilized as a vodka or wine barrel. On the other hand, tyloses impede the flow in vessel lumen, thus prolonging the time for woods to dry. It may also cause defects during such processes. Chang et al. (2017) argue that the absence of tyloses facilitates the drying process despite relatively poor conditions for drying compared to the conventional conditions regarding oak trees.

Deciduous tree species are spreading across South Korea with the acceleration of climate change. Oak tree species account for the largest share of the deciduous tree species, implying the importance of identifying appropriate uses of the species. In this study, therefore, six oak species most common in South Korea were chosen including Quercus mongolica, Quercus dentata, Quercus acutissima, Quercus serrata, Quercus aliena, and Quercus variabilis. All samples were collected from the six species in Yeongdong, Chungcheong province. The presence and the number of tyloses and correlations between lumen area of large vessel and tyloses in the samples were analyzed. Kim (2011) reported a difference in dynamic characteristics between normal wood and tension wood of Quercus mongolica, arguing that the reason for the difference lies in anatomical differences between the two types. South Korean forests also have the peculiarity that they are sloped (on average $5.7^{\circ}$ ), thus affecting the proportion of tension wood and the way that tension wood grows. Wood is classified as tension wood when the pith axis of hard wood that has grown in a slope becomes inclined to the sloped direction and the growth rings of the wood grow in an asymmetrical way around the pith. It is therefore common that tension wood can be observed in South Korea. It is against these backdrops that not only normal wood but also tension wood of the samples were examined in this study. It is expected that this study will provide fundamental data to select species when utilizing oak trees. 


\section{EXPERIMENTAL}

\section{Materials}

Samples of tension wood, which was identified according to the width of growth rings and the pith position among all cross-section samples, were sorted out. After sorting out normal and tension woods from the six oak species that grew in Yeongdong, North Chungcheong province, the cross-sections were divided into juvenile wood, heartwood, and sapwood (Table 1). Juvenile wood samples were obtained from parts between the pith and the tenth growth ring. The criterion to obtain the juvenile wood samples was based on Hwang (2002), saying that parts between the pith and the thirteenth growth ring can be considered as juvenile wood according to his analysis of vessel lumen area.

Table 1. Specimen and Number of Measurements

\begin{tabular}{|c|c|c|}
\hline Tree Species (English Notation, Sample ID) & $\begin{array}{c}\text { Number of } \\
\text { Samples for } \\
\text { normal Wood }\end{array}$ & $\begin{array}{c}\text { Number of } \\
\text { Samples for } \\
\text { Tension Wood }\end{array}$ \\
\hline Quercus aliena BI. (Galcham oak: Go) & 12 & 12 \\
\hline Quercus variabilis Blume (Oriental cork oak: Oo) & 12 & 12 \\
\hline Quercus serrata Thunb. ex Murray (Jolcham oak: Jo) & 12 & 12 \\
\hline Quercus acutissima Carruth. (Swatooth oak, So) & 12 & 12 \\
\hline Quercus dentata (Korean oak: Ko) & 12 & 12 \\
\hline $\begin{array}{c}\text { Quercus mongolica Fisch. ex Ledeb. (Mongolica oak: } \\
\text { Mo) }\end{array}$ & 12 & \\
\hline
\end{tabular}

\section{Methods}

Sample slice production for large vessel observation

Preparations for the observation of tyloses were made. Each Quercus spp. was collected from each cross-section part, cut into $10 \times 10 \times 10 \mathrm{~mm}^{3}$ dimensions. It was then softened in a solution of distilled water and glycerin at a ratio of 1:3. The slices stayed in the solution for an average of 2 to 3 days.

The softened samples were cut with a cross-section with 20 - to $30 \mu \mathrm{m}$ thickness. Next, the slices were dyed in 1\% solution of safranine (SAMCHUN/Daejung/Korea), and were dehydrated sequentially with alcohol of varying potency $(30,50,70$, and $99.9 \%)$. The last step in the preparatory stage was to apply paraffin. Two preparations of cross-sections were made according to the type of wood (normal and tension wood) and parts (juvenile wood, heartwood and sapwood) to estimate the lumen area of large vessel and observe the distribution of tyloses in a total of 50 large vessels. Statistically significant differences in the observed values of the six species were tested. The difference tests were made through $\mathrm{F}$ tests and $\mathrm{T}$ tests at a level of 0.05 in a software, Excel (Microsoft, USA).

\section{Identification of tyloses in large vessels and the estimation of large vessel lumen area}

The presence of tyloses in a large vessel was identified on a cross-section, and the lumen area of the large vessel was measured (Fig. 1). Thirty large vessels were examined for each region of juvenile wood, heartwood, and sapwood. The total number of vessels was determined and the number of tyloses was indicated as a percentage. 


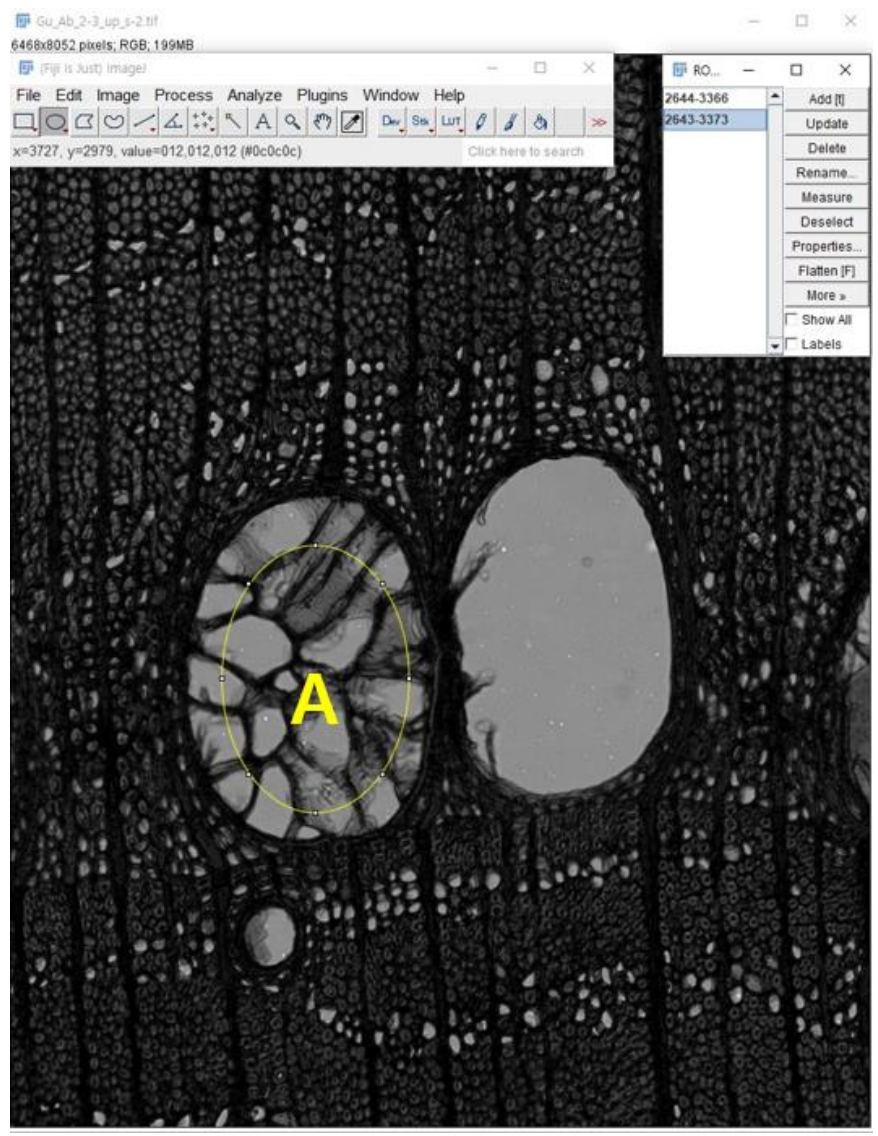

Fig. 1. Method to measure tyloses (Image J/JAVA, A: Tyloses)

\section{RESULTS AND DISCUSSION}

\section{Estimation of Large Vessel Lumen Area per Species}

The amount of water transported depends on the large vessel lumen area of oak trees. Ring porous woods, such as oak, are known to form large vessels in their early wood with few leaves, thus finishing the formation of cells within around 24 days (Sass et al. 2011). Therefore, late winter moisture stored in the soil is an important factor when large vessels are created (Jeong et al. 2017). Among the oak trees in this study, the large vessel area of normal wood was most abundant in sapwood, which was followed by heartwood and juvenile wood. Tension wood produced similar results. It was discovered that the large vessel area of juvenile wood of normal wood was on average $51572 \pm 15532 \mu \mathrm{m}^{2}$. The average area of heartwood was $90154 \pm 21021 \mu \mathrm{m}^{2}$, while that of sapwood was $101732 \pm$ $35193 \mu^{2}$. Regarding tension wood, on the other hand, the area of juvenile wood was $51259 \pm 11680 \mu \mathrm{m}^{2}$. That of heartwood was $90552 \pm 26380 \mu \mathrm{m}^{2}$ while that of sapwood was $94974 \pm 23852 \mu \mathrm{m}^{2}$. The followings are orders of tyloses from largest to smallest, sorted by species, type, and conditions of the wood (Table 2). For juvenile wood of normal wood, the order was $Q$. serrata $>Q$. acutissima $>Q$. variabilis $>Q$. dentate $>Q$. aliena; for heartwood of normal wood, the order was $Q$. aliena $>Q$. acutissima $>Q$. variabilis $>$ $Q$. serrata $>Q$. dentate $>Q$. mongolica; for sapwood of normal wood, the order was $Q$. variabilis $>Q$. acutissima $>Q$. variabilis $>Q$. dentate $>Q$. aliena $>Q$. mongolica; for 
juvenile wood of tension wood, the order was $Q$. serrata $>Q$. variabilis $>Q$. acutissima $>$ $Q$. dentate $>Q$. mongolica $>Q$. aliena; for heartwood, the order was $Q$. variabilis $>Q$. serrata $>Q$. acutissima $>Q$. dentate $>Q$. mongolica $>Q$. aliena , for sapwood, the order was $Q$. acutissima $>Q$. serrata $>Q$. variabilis $>Q$. mongolica $>Q$. aliena $>Q$. dentata.

Few marked characteristics were found in the type and conditions of the species. Statistically significant differences were revealed in all the three areas of both the normal wood and the tension wood. The size of the compositional cells in wood determines the material of wood (Zhang 1997). Therefore, it is determined that there is a difference in the material of normal wood and tension wood even if they are of the same species.
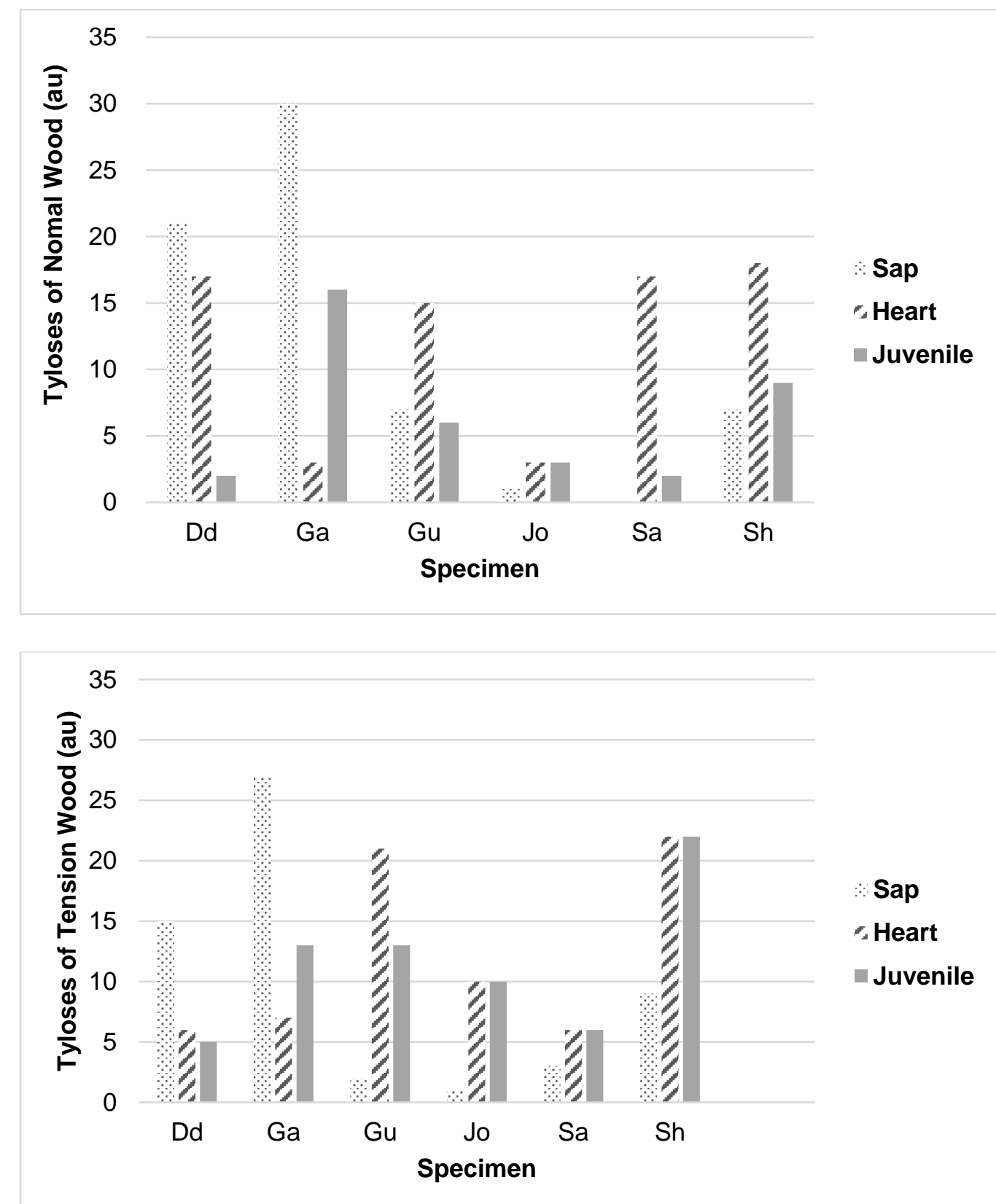

Fig. 2. The number of tyloses in normal wood and tension wood 
Table 2. Lumen Area of Large Vessel (Unit: $\left.\mu m^{2}\right)$

\begin{tabular}{|c|c|c|c|c|c|c|}
\hline \multirow{2}{*}{ No. } & \multicolumn{3}{|c|}{ Normal Wood } & \multicolumn{3}{c|}{ Tension Wood } \\
\cline { 2 - 7 } & Juvenile & Heart & Sap & Juvenile & Heart & Sap \\
\hline \multirow{2}{*}{ Go } & $\begin{array}{c}33998 \\
( \pm 3303)\end{array}$ & $\begin{array}{c}100961 \\
( \pm 17550)\end{array}$ & $\begin{array}{c}77210 \\
( \pm 14068)\end{array}$ & $\begin{array}{c}30467 \\
( \pm 7296)\end{array}$ & $\begin{array}{c}67295 \\
( \pm 12141)\end{array}$ & $\begin{array}{c}76772 \\
( \pm 17384)\end{array}$ \\
\hline \multirow{2}{*}{ Oo } & 47890 & 93262 & 102342 & 58676 & 105191 & 99193 \\
& $( \pm 9335)$ & $( \pm 11654)$ & $( \pm 10788)$ & $( \pm 16458)$ & $( \pm 15562)$ & $( \pm 20281)$ \\
\hline \multirow{2}{*}{ Jo } & 70356 & 84740 & 112834 & 60533 & 86710 & 99330 \\
& $( \pm 11426)$ & $( \pm 18587)$ & $( \pm 10736)$ & $( \pm 12068)$ & $( \pm 13815)$ & $( \pm 19993)$ \\
\hline So & 61046 & 94407 & 104707 & 58100 & 82484 & 99347 \\
& $( \pm 9056)$ & $( \pm 11720)$ & $( \pm 15875)$ & $( \pm 5844)$ & $( \pm 7599)$ & $( \pm 16100)$ \\
\hline Ko & 46816 & 73017 & 86370 & 55284 & 74246 & 74510 \\
& $( \pm 6978)$ & $( \pm 6971)$ & $( \pm 9323)$ & $( \pm 7594)$ & $( \pm 17571)$ & $( \pm 21386)$ \\
\hline Mo & 33639 & 64552 & 65187 & $\begin{array}{c}44493 \\
( \pm 937)\end{array}$ & $\begin{array}{c}72721 \\
( \pm 13918)\end{array}$ & $\begin{array}{c}81690 \\
( \pm 10008)\end{array}$ \\
\hline
\end{tabular}

\section{Analysis and Quantitative Assessment of Tyloses by Species}

Tyloses are generated when the wood becomes not just lignified but also damaged (Kwon et al. 2020). Tyloses also begin to emerge between May and June and the amount grows until the autumn (Gonzalo et al. 2018). In the present work, tyloses were observed in juvenile wood, heartwood, and sapwood. As for the normal wood, it was heartwood that had the highest number of tyloses, followed by sapwood and juvenile wood. Likewise, tyloses concerning the tension wood were largest in heartwood but bigger in juvenile wood than in sapwood.

The results by species showed that in the normal wood, Quercus aliena had the largest tyloses, followed by Quercus dentata, Quercus mongolica, Quercus variabilis, Quercus acutissima, and Quercus serrata (Fig. 2). In contrast, for the tension wood tyloses were highest in Quercus mongolica, followed by Quercus aliena, Quercus variabilis, Quercus dentata, Quercus serrata, and Quercus acutissima in order (Fig. 3). It can be argued that tyloses exist in all the species, with no clear differences between species, conditions, and parts. Tyloses are generated even in drought or frost. More embolized stems arise from drought and frost (Hervé and Melvin 1990). Thus, it can be assumed that the number of tyloses is likely to be affected by its surroundings.

\section{Tyloses Existence Analysis by Large Vessel Lumen Area}

The large vessel lumen area depends on the rainfall a year before it is formed, and the flow amount of nutriment through the area is determined by the area size (Jeong et al., 2017). A test of significant differences between species (Table 2) revealed no distinct trends, despite the differences between some species. Analysis of a relationship between the large vessel lumen area and the existence of tyloses showed that a larger vessel lumen area resulted in the smaller number of tyloses. In contrast, an inverse trend was found in heartwood of the tension wood. According to previous research, no correlations are identified between the diameter of large vessels and the number of tyloses (Gonzalo et al. 2018). Far more samples are needed in further research to establish the correlations. 

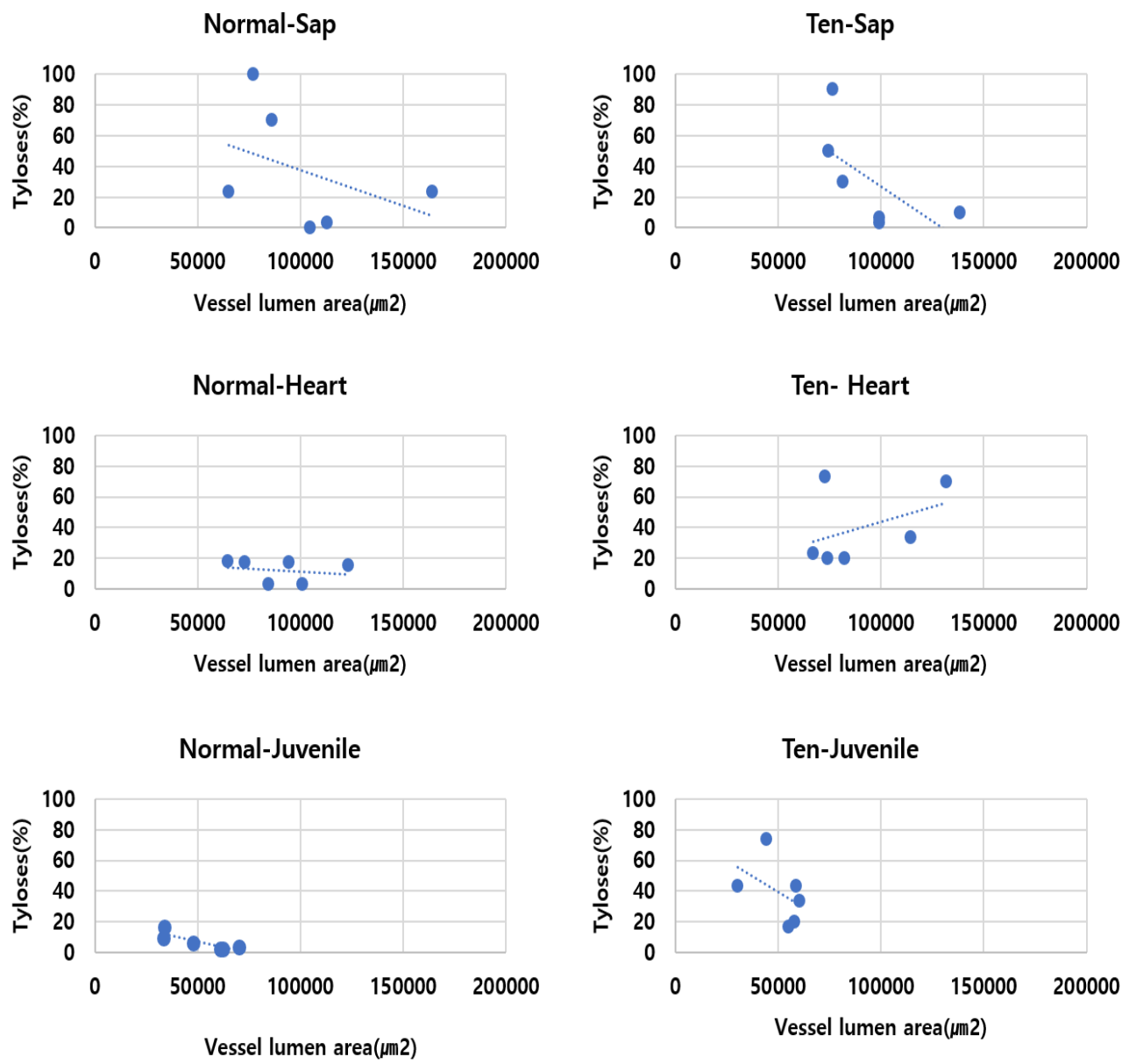

Fig. 3. Relationships between vessel lumen area and tyloses

\section{CONCLUSIONS}

This study was conducted to devise ways of expanding the use of deciduous tree species that are gradually dominating South Korean forests. To this end, six oak species that are commonly used to produce liquor barrels in the country were selected. Then, normal wood and tension wood were sorted out from the samples. Next, they were also divided according to three parts including juvenile wood, heartwood and sapwood. The presence and the number of tyloses, as wells as the lumen area of large vessels were estimated.

1. It was revealed that all the six oak species that are most common in South Korea are white oak and they show the normal type of tyloses.

2. In both normal and tension woods, the large vessel area was biggest in sapwood, followed by heartwood, and then juvenile wood. Significant differences were found between all the given subjects. It can thus be assumed that quality differences would exist between the normal and tension woods even in an identical species. 
3. The difference in the number of tyloses between species was discovered despite their presence in both the normal and tension woods of the six oak species. As for normal wood, it was heartwood that formed the largest number, followed by sapwood and juvenile wood. Regarding the tension wood, it was also heartwood that had the biggest number of tyloses, but the number was larger in juvenile wood than in sapwood. Then, a comparison of the number of tyloses between species revealed that, in the normal wood, Quercus aliena BI. had the largest tyloses, followed by Q. dentata, Q. mongolica Fisch. ex Ledeb., $Q$. variabilis Blume, $Q$. acutissima Carruth., and $Q$. serrata Thunb. ex Murray. In contrast, for the tension wood tyloses were highest in $Q$. mongolica Fisch. ex Ledeb., followed by $Q$. aliena BI., $Q$. variabilis Blume, $Q$. dentata, $Q$. serrata Thunb. ex Murray, and Q. acutissima Carruth.

4. The analysis of the relationship between the large vessel lumen area and tyloses showed that tyloses decreased with the growing area. Yet, the inverse tendency was observed in heartwood of the tension wood, thus meaning that species are not attributable to the difference. Therefore, for the relationship to be determined, far much larger samples are needed in further research.

It is expected that the results this study proposes will be used as fundamental data to determine species when utilizing oak species that are spreading in South Korea with climate change.

\section{ACKNOWLEDGMENTS}

This paper was supported by the Korea Food Research Institute (KFRI Project No. E0201100) and the National Research Foundation of Korea (NRF) (Project No. 2018M3C1B505214813).

\section{REFERENCES CITED}

Cerdán, T. G., Mozaz, S. R., and Azpilicueta, C. A. (2002). "Volatile composition of aged wine in used barrels of French oak and American oak," J. Food Res. Int. 35(7), 603-310. DOI: 10.1016/S0963-9969(01)00151-X

Chang, Y. S., Shin, H. K., Kim, S. J., Han, Y. J., Kim, M. J., Eom, C. D., Lee, Y. G., and Shim, K. B. (2017). "Evaluation of drying properties and yields of domestic Quercus species for enhancing utilization,” J. Korean Wood Sci. Technol. 45(5), 622-628. DOI: $10.5658 /$ WOOD.2017.45.5.622

Frangipane, M. T., and De Santis, D. (2007) "Influence of oak woods of different geographical origins on quality of wine aged in barriques and using oak chips," Food Chemistry 103, 46-54. DOI: 10.1016/j.foodchem.2006.07.070

Gonzalo, P. L., Vicente, R., Rosa, A. V., and Ignacio, G. G. (2018). "Do ring-porous oaks prioritize earlywood vessel efficiency over safety? Environmental effects on vessel diameter and tylosis formation," Agricultural and Forest Meteorology 248, 205-214. DOI: 10.1016/j.agrformet.2017.09.022

Hervé, C., and Melvn T. (1990). "Xylem dysfunction in Quercus: Vessel size, tylosis, 
cavitation and seasonal changes in embolism," Tree Physiology 6, 393-407. DOI: 10.1093/treephys/6.4.393

Hwang, W. J., Kwon, G. J., Park, W. G., Bae, Y. S., Kim, N. H. (2002). “Anatomical characteristics of major Korean ash species," J. Korean Wood Sci. Technol. 30(2), 7986.

Jeong, H. M., Kim, Y. J., and Seo, J. W. (2017). "Relationships between vessel lumen area time series of Quercus spp. at Mt Songni and corresponding climatic factors," Journal of the Korean Wood Science and Technology 45(1), 72-84. DOI: 10.5658/WOOD.2017.45.1.72

Kwon, S. M., Kwon, G. J., Jang, J. H., and Kim, N. H. (2011). "Fractography of sound and tension woods of Quercus mongolica by shear and bending stress," J. Korean Wood Sci. Technol. 38(4), 351-3583. DOI:10.5658/WOOD.2011.39.4.351

Kwon, O. K., Kim, N. H., Kim, J. S., and Seo, J. W. (2020). "Wood anatomy," Journal of the Korean Wood Science and Technology 21(2), 43-50.

Lee, B. D., and Park, B. S. (2009). "Anatomical characteristics of Korean mistletoe Viscum album var. coloratum (Kom.) Ohwi stem," Korean Journal of Plant Resources 22(4), 287-292.

Lidija, M. (1975). "Formation of tylosis in elfled Quercus rubra L," Wood Science and Technology 9, 3-14.

Park, S. J., Lee, W. Y., and Lee, H. H. (2006). Wood Anatomy, Hyang Moon Sa.

Sass, U., Sabajo, C. R., and Ouden, J. (2011). "Vessel formation in relation to leaf phenology in pedunculate oak and European ash," Dendrochronologia 29, 171-175. DOI: 10.1016/j.dendro.2011.01.002

Sayaka, T., Naoki, O., and Tadashi, N. (2013). "Relationship between the timing of vessel formation and leaf phenology in ten ring-porous and diffuse deciduous tree species," Ecol Res. 28, 615-624. DOI: 10.1007/s11284-013-1053-x

You, H. S. (2013). "Q-methodology study on the perception of domestic wine market for wine mania," Northeast Asia tourism research 9(1).

Zhang, S. Y. (1997). "Wood specific gravity-mechanical property relationship at species level," Wood Science and Technology 31, 181-191.

Article submitted: September 13, 2021; Peer review completed: October 23, 2021;

Revised version received and accepted: December 15, 2021; Published: January 7, 2022. DOI: 10.15376/biores.17.1.1364-1372 